\title{
The effects of smoking on adolescent trauma patients: a propensity-score-matched analysis
}

\author{
Greg Garo Kojayan $^{1} \cdot$ Areg Grigorian ${ }^{1} \cdot$ Sebastian D. Schubl ${ }^{1}$ - Catherine M. Kuza ${ }^{2} \cdot$ Matthew Dolich $^{1} \cdot$ Rame Bashir $^{1}$. \\ Jeffry Nahmias ${ }^{1}$
}

Accepted: 24 March 2020 / Published online: 31 March 2020

(c) Springer-Verlag GmbH Germany, part of Springer Nature 2020

\begin{abstract}
Purpose Cigarettes have been demonstrated to be toxic to the pulmonary connective tissue by impairing the lung's ability to clear debris, resulting in infection and acute respiratory distress syndrome (ARDS). Approximately 8\% of adolescents are smokers. We hypothesized that adolescent trauma patients who smoke have a higher rate of ARDS and pneumonia when compared to non-smokers.

Methods The Trauma Quality Improvement Program (2014-2016) was queried for adolescent trauma patients aged 13-17 years. Adolescent smokers were 1:2 propensity-score-matched to non-smokers based on age, comorbidities, and injury type. Data were analyzed using chi square for categorical data and Mann-Whitney $U$ test for continuous data.

Results From 32,610 adolescent patients, 997 (3.1\%) were smokers. After matching, 459 smokers were compared to 918 non-smokers. There were no differences in matched characteristics. Compared to non-smokers, smokers had an increased rate of pneumonia $(3.1 \%$ vs. $1.1 \%, p=0.01)$ but not ARDS $(0.2 \%$ vs. $0 \%, p=0.16)$. Compared to the non-smoking group, the smokers had a longer median total hospital length-of-stay ( 3 vs. 2 days, $p=0.01$ ) and no difference in overall mortality ( $1.5 \%$ vs. $2.4 \%, p=0.29$ ).

Conclusion Smoking is associated with an increased rate of pneumonia in adolescent trauma patients. Future research should target smoking cessation and/or interventions to mitigate the deleterious effects of smoking in this population.
\end{abstract}

Keywords Pediatric $\cdot$ Smokers $\cdot$ Trauma surgery $\cdot$ ARDS $\cdot$ Pneumonia $\cdot$ TQIP

\section{Introduction}

Tobacco consumption is currently the leading cause of preventable death worldwide, claiming approximately 5 million lives every year since 1990 [1,2]. Although cigarette use among the youth has been declining since 2011, more than 300 adolescents each day become daily cigarette smokers in the United States [3]. Teenagers who smoke cigarettes are more likely to use other substances (i.e., alcohol and marijuana) and be involved in risky behaviors, such as violence,

Greg Garo Kojayan

kojayang@uci.edu

1 Division of Trauma, Burns and Surgical Critical Care, Department of Surgery, University of California, Irvine Medical Center, 333 The City Blvd West, Suite 1600, Orange, CA 92868-3298, USA

2 Department of Anesthesiology, University of Southern California, Los Angeles, CA, USA theft, and suicide $[4,5]$; this behavior increases the risk of being involved in trauma [6].

There are over 7000 chemicals in tobacco smoke [7]. Acrolein, one of the cigarette's many carcinogens, has been demonstrated to increase lung vascular permeability by disrupting adherens junctions and actin fibers [8,9]. Other chemicals in cigarette smoke are known to cause cellular insult, which increases the risk of bacterial pneumonia [10, 11]. Additionally, cigarette smoking causes an increase in reactive oxygen species and decreases surfactant production, both of which are underlying pathophysiological mechanisms of acute respiratory distress syndrome (ARDS) [12-17]. Approximately 200,000 patients in the United States develop ARDS each year, with up to $4.4 \%$ occurring in trauma patients $[18,19]$. One retrospective cohort study suggested that $50 \%$ of ARDS cases were associated with cigarette smoking [20]. Similarly, a prospective study on blunt trauma patients found that cigarette smoking increased platelet aggregation and was associated with an increased 
risk of ARDS [21]. Additionally, there are studies that link smoking to the development of pneumonia [22, 23], and many studies show a high incidence of pneumonia in trauma patients [24-27]. However, to our knowledge, there are no studies evaluating the rate of pneumonia and ARDS in adolescent trauma smokers. We hypothesized that adolescent smokers with traumatic injury have a higher rate of ARDS and pneumonia compared to non-smokers. In addition, we also sought to provide a descriptive analysis of adolescent smokers involved in trauma.

\section{Methods}

This study was approved by the Institutional Review Board at the University of California, Irvine. A retrospective analysis of the Pediatric Trauma Quality Improvement Program (TQIP) was performed between 2014 and 2016 to identify adolescent trauma patients between the ages of 13 and 17 . Patients who were current smokers were compared to nonsmokers. This is listed as one of the 30-required comorbidities to be reported in TQIP and is defined by "A patient who reports smoking cigarettes every day or some days within the last 12 months. This excludes patients who smoke cigars or pipes or use smokeless tobacco (chewing tobacco or snuff)".

The primary outcomes were the development of ARDS or pneumonia. Other measured outcomes included total hospital length of stay (LOS), intensive care unit (ICU) LOS, ventilator days, in-hospital mortality, and other in-hospital complications including cardiac arrest, acute kidney injury (AKI), decubitus ulcer, deep site infection, compartment syndrome, deep vein thrombosis (DVT), pulmonary embolism, and cerebrovascular accident.

Frequency statistics were performed for all groups. A Mann-Whitney $U$ test was used to compare continuous variables and chi-square was used to compare categorical variables for bivariate analysis. Categorical data were reported as percentages, and continuous data were reported as medians with interquartile range or as means with standard deviations. Due to the observed imbalance in the sample size between the two groups, smokers were matched with non-smokers using a 1:2 propensity score model based on age, gender, hypotension on admission (systolic blood pressure $<90 \mathrm{mmHg}$ ), injury severity score (ISS), as well as injuries to the brain, spine, upper and lower extremity, lung, heart, stomach, small intestine, colorectal, pancreas, liver, spleen, and kidney. Injuries were defined by appropriate international-classification of diseases version-9 (ICD-9) diagnosis codes. We included in our analysis only those cases that were within 0.001 of the estimated logit. This technique of defining the closeness of a matched case is termed caliper matching and is a validated method of emulating randomization in observational studies [28]. Once propensity scores were calculated for each case, one smoker and two non-smoking-matched patients were identified from the sample. If a patient that smoked did not have a close match available, they were excluded from any further analysis. All $p$ values were two sided, with a statistical significance level of $<0.05$. All analyses were performed with IBM SPSS Statistics for Windows (Version 24, IBM Corp., Armonk, NY).

\section{Results}

\section{Demographics and injury types}

From 32,610 adolescent trauma patients, 997 (3.1\%) were smokers. Of the smokers, 759 (76.1\%) were male with a median age of 17 years and a median ISS of 9 . After propensity matching, 459 smokers were compared to 918 nonsmokers. There were 538 patients who did not fit into our propensity-matched model, and thus, were excluded from the analysis. There were no differences among the smokers and non-smokers with respect to median age (16 vs. 16 years, $p=0.99)$, male gender ( $75.6 \%$ vs. $73.7 \%, p=0.51)$, hypotension on admission ( $1.3 \%$ vs. $1.9 \%, p=0.46)$, and median ISS (9 vs. $9, p=0.20$ ) (Table 1 ). The injury profile was similar

Table 1 Demographics of adolescent trauma patients stratified by smoking status

\begin{tabular}{|c|c|c|c|c|}
\hline Characteristic & All smokers $(n=997)$ & Non-smokers $(n=918)$ & Smokers $(n=459)$ & $p$ value \\
\hline Age, year, median (IQR) & $17.0(16,17)$ & $16.0(16,17)$ & $16.0(16,17)$ & 0.99 \\
\hline Male, $n(\%)$ & $759(76.1 \%)$ & $677(73.7 \%)$ & $346(75.4 \%)$ & 0.51 \\
\hline ISS, median (IQR) & $9.0(6,12)$ & $9(5,12)$ & $9(5,13)$ & 0.20 \\
\hline Hypotensive on admission, $n(\%)$ & $14(1.4 \%)$ & $17(1.9 \%)$ & $6(1.3 \%)$ & 0.46 \\
\hline \multicolumn{5}{|l|}{ Comorbidities, $n(\%)$} \\
\hline Diabetes & $3(0.3 \%)$ & 0 & $1(0.2 \%)$ & 0.16 \\
\hline Hypertension & $4(0.4 \%)$ & $2(0.2 \%)$ & $2(0.4 \%)$ & 0.48 \\
\hline COPD & $19(1.9 \%)$ & $15(1.6 \%)$ & $12(2.6 \%)$ & 0.22 \\
\hline
\end{tabular}

$I S S$ injury severity score, IQR interquartile range, $C O P D$ chronic obstructive pulmonary disease 
for both groups, with most patients sustaining blunt trauma ( $86.1 \%$ vs. $89.2 \%, p=0.10)$, and presenting with a traumatic brain injury $(38.6 \%$ vs. $39.0 \%, p=0.88)($ Table 2$)$.

\section{Primary outcomes and hospital outcomes/ complications}

Compared to non-smokers, smokers had an increased rate of pneumonia ( $3.1 \%$ vs. $1.1 \%, p=0.01)$. There was no difference in the rate of all other in-hospital complications including ARDS ( $0.2 \%$ vs. $0 \%, p=0.16)$, DVT $(0.2 \%$ vs. $1.0 \%$, $p=0.12$ ), and AKI ( $0 \%$ vs. $0.1 \%, p=0.48)$.

Smokers had a longer median hospital LOS (3 vs. 2 days, $p=0.01)$ compared to non-smokers. There was no difference in mortality ( $1.5 \%$ vs. $2.4 \%, p=0.29)$, ICU LOS ( 3 vs. 2 days, $p=0.55$ ), or ventilator days ( 3 vs. 2 days, $p=0.75$ ) between the two groups (Table 3 ).

\section{Discussion}

While there is existing literature on the effects of smoking on adult trauma patient outcomes, to our knowledge, this is the first study to evaluate the effects of smoking on outcomes in the adolescent trauma patient population. Our retrospective analysis reported that $3.1 \%$ of adolescent trauma patients were cigarette smokers. Compared to non-smoking trauma patients, smokers were more likely to develop pneumonia and have longer LOS, but there was no difference between the groups with respect to mortality or ARDS, the latter being an extremely rare complication in this population.

Cigarette smoking impedes the lung's healing ability and predisposes it to injury following an inciting event. Previous studies on adult smokers have demonstrated increased rates of ARDS secondary to lung injury when compared to nonsmokers in both critically ill and trauma patients [21, 29-32]. In a study of 74 patients by Panzer et al., critically ill adult trauma smokers had an altered respiratory bacterial community including enrichment of Enterobacteriaceae associated with an increased incidence of ARDS [29]. There is a progressive increase in incidence of ARDS following trauma with increasing age, with a peak incidence in patients aged 60-69 years [33]. Our results demonstrated a low incidence $(0.3 \%)$ of ARDS in the adolescent trauma population, with all cases occurring in smokers; however, this was not statistically significant in comparison to the non-smokers. Our findings are consistent with other pediatric studies, which report a low incidence of ARDS in non-trauma patients. Furthermore, the rate of ARDS has previously been shown to be low specifically in pediatric trauma patients with Roulet et al. finding an incidence of $0.5 \%$ of all pediatric trauma admissions and Killen et al. demonstrating an incidence of $1.8 \%$ of all pediatric patients admitted to an ICU $[34,35]$. Lee et al. postulated the lower rate of ARDS and associated mortality in younger patients is due to greater capacity for repair, and altered cytokine burden including interleukin-1 and -8 , and tissue necrosis factor alpha [36]. In addition, there is also likely a dose/duration association with smoking that may have not reached a critical threshold for these adolescents [37]. Future investigations regarding the pathophysiology that protects adolescents from developing ARDS appears warranted.

Smoking increases the risk of inflammatory and infectious complications in trauma patients. Bagaitkar et al. demonstrated that adult patients who smoke cigarettes have a 2.6-fold increased risk of developing pneumonia [22].
Table 2 Injury type in adolescent trauma patients stratified by smoking status

\begin{tabular}{llcll}
\hline Injury type, $n(\%)$ & All smokers $(n=997)$ & Non-smoker $(n=918)$ & Smoker $(n=459)$ & $p$ value \\
\hline Blunt trauma & $871(87.4 \%)$ & $794(89.2 \%)$ & $384(86.1 \%)$ & 0.10 \\
TBI & $238(23.9 \%)$ & $358(39.0 \%)$ & $177(38.6 \%)$ & 0.88 \\
Spine & $125(12.5 \%)$ & $163(17.8 \%)$ & $83(18.1 \%)$ & 0.88 \\
Upper extremity & $139(13.9 \%)$ & $177(19.3 \%)$ & $98(21.4 \%)$ & 0.37 \\
Lower extremity & $132(13.2 \%)$ & $170(18.5 \%)$ & $96(20.9 \%)$ & 0.29 \\
Esophagus & 0 & $1(0.1 \%)$ & 0 & 0.48 \\
Colorectal & $13(1.3 \%)$ & $12(1.3 \%)$ & $6(1.3 \%)$ & 1.00 \\
Pancreas & $2(0.2 \%)$ & $1(0.1 \%)$ & $1(0.2 \%)$ & 0.62 \\
Stomach & $6(0.6 \%)$ & $1(0.1 \%)$ & 0 & 0.48 \\
Liver & $35(3.5 \%)$ & $42(4.6 \%)$ & $15(3.3 \%)$ & 0.25 \\
Small intestine & $14(1.4 \%)$ & $9(1.0 \%)$ & $8(1.7 \%)$ & 0.23 \\
Spleen & $33(3.3 \%)$ & $32(3.5 \%)$ & $22(4.8 \%)$ & 0.24 \\
Kidney & $25(2.5 \%)$ & $21(2.3 \%)$ & $10(2.2 \%)$ & 0.90 \\
Lung & $137(13.7 \%)$ & $145(15.8 \%)$ & $73(15.9 \%)$ & 0.96 \\
Heart & $2(0.2 \%)$ & $2(0.2 \%)$ & $2(0.4 \%)$ & 0.48 \\
\hline
\end{tabular}

$T B I$ traumatic brain injury 
Table 3 Clinical outcomes in adolescent trauma patients stratified by smoking status

\begin{tabular}{|c|c|c|c|c|}
\hline Outcome & All smokers $(n=997)$ & $\begin{array}{l}\text { Non- } \\
\text { smokers } \\
(n=918)\end{array}$ & Smokers $(n=459)$ & $p$ value \\
\hline LOS, days, median (IQR) & $3.0(2,4)$ & $2.0(2,4)$ & $3.0(2,5)$ & 0.01 \\
\hline ICU, days, median (IQR) & $3.0(1,4)$ & $2.0(1,4)$ & $3.0(2,5)$ & 0.55 \\
\hline Ventilator, days, median (IQR) & $2.0(1,4)$ & $2.0(1,4)$ & $3.0(1,10.5)$ & 0.75 \\
\hline \multicolumn{5}{|l|}{ Complications, $n(\%)$} \\
\hline Unplanned ICU, $n(\%)$ & $7(0.7 \%)$ & $8(0.9 \%)$ & $3(0.7 \%)$ & 0.67 \\
\hline Unplanned intubation, $n(\%)$ & $2(0.2 \%)$ & $2.0(0.2 \%)$ & $1.0(0.2 \%)$ & 1.00 \\
\hline Unplanned return to $\mathrm{OR}, n(\%)$ & $6(0.6 \%)$ & $3.0(0.3 \%)$ & $6.0(1.3 \%)$ & 0.03 \\
\hline Acute respiratory distress syndrome & $3(0.3 \%)$ & 0 & $1(0.2 \%)$ & 0.16 \\
\hline Acute kidney injury & $2(0.2 \%)$ & $1(0.1 \%)$ & 0 & 0.48 \\
\hline Cardiac arrest & $2(0.2 \%)$ & $4(0.4 \%)$ & $1(0.2 \%)$ & 0.53 \\
\hline Decubitus ulcer & $2(0.2 \%)$ & $3(0.3 \%)$ & $1(0.2 \%)$ & 0.72 \\
\hline Deep site infection & $2(0.2 \%)$ & $1(0.1 \%)$ & $1(0.2 \%)$ & 0.62 \\
\hline Compartment syndrome & $1(0.1 \%)$ & 0 & $1(0.2 \%)$ & 0.16 \\
\hline Deep vein thrombosis & $4(0.4 \%)$ & $9(1.0 \%)$ & $1(0.2 \%)$ & 0.12 \\
\hline Graft failure & $2(0.2 \%)$ & $2(0.2 \%)$ & $2(0.4 \%)$ & 0.48 \\
\hline Pneumonia & $14(1.4 \%)$ & $10(1.1 \%)$ & $14(3.1 \%)$ & 0.01 \\
\hline Pulmonary embolism & 0 & $1(0.1 \%)$ & 0 & 0.48 \\
\hline Cerebrovascular accident & $2(0.2 \%)$ & $1(0.1 \%)$ & $1(0.2 \%)$ & 0.62 \\
\hline Superficial infection & $4(0.4 \%)$ & $1(0.1 \%)$ & $3(0.7 \%)$ & 0.08 \\
\hline Urinary tract infection & $2(0.2 \%)$ & $2(0.2 \%)$ & $2(0.4 \%)$ & 0.48 \\
\hline CRBSI & 0 & $1(0.1 \%)$ & 0 & 0.48 \\
\hline Severe sepsis & $1(0.1 \%)$ & $1(0.1 \%)$ & 0 & 0.48 \\
\hline Other & $66(6.6 \%)$ & $78(8.5 \%)$ & $33(7.2 \%)$ & 0.40 \\
\hline Mortality, $n(\%)$ & $9(0.9 \%)$ & $22(2.4 \%)$ & $7(1.5 \%)$ & 0.29 \\
\hline
\end{tabular}

$L O S$ length of stay, IQR interquartile range, OR operating room, ICU intensive care unit, CRBSI catheterrelated bloodstream infection
However, Ferro et al.'s retrospective analysis of adult trauma patients demonstrated no difference in the rate of pneumonia in smokers compared to non-smokers [38]. Our data are the first to suggest an increased incidence of pneumonia in adolescent trauma patients who smoke. One explanation for the difference in results is that unlike the study by Ferro et al., we propensity-matched smokers to similar non-smokers based on comorbidities and injuries. In addition to the morbidity associated with pneumonia, treatment costs $\$ 6042$ on average for younger patients with the majority of the cost due to the hospital LOS $[39,40]$. Our data corroborate this finding as adolescent smoking trauma patients were demonstrated to have a longer LOS. While there is certainly a dose-response increase in respiratory complications caused by cigarette smoking, this study demonstrates an increased rate of pneumonia and hospital LOS despite only minimal cumulative exposure. Our results suggest there is no safe smoking age, and by understanding this risk, clinicians can counsel their adolescent patients on the dangers of both short- and long-term cigarette smoking.

Trauma patients who smoke do not consistently have worse outcomes compared to non-smokers [41]. In fact, several studies have demonstrated a lower mortality in adult smokers following a traumatic injury [38, 42, 43]. This phenomenon is termed the "smoker's paradox," and was originally described in adult patients who sustained acute myocardial infarction [44-46]. One proposed mechanism is that smoking increases coagulability, which may be beneficial during an acute hemorrhagic injury [47]. Another possible mechanism is that exposure to cigarette smoke causes adaptation to hypoxemia such that periods of acute ischemia associated with hemorrhagic shock from trauma have less of a deleterious effect [48]. There are currently no studies demonstrating the "smoker's paradox" in the adolescent population regardless of the disease process. Our data demonstrated that smoking had no effect on risk of survival in adolescent trauma patients. In fact, the only two complications that were increased in this population were pneumonia and an unplanned return to the operating room. This may suggest that the protective mechanism of cigarette smoking has not yet developed in adolescent smokers who likely have not smoked for as long as adults who exhibit the smoker's paradox. Future combined clinical and basic science research to evaluate this is needed. 
As a large retrospective database study, there are inherent limitations including reporting bias, coding errors, and missing data. A significant limitation is that 538 patients did not fit into our propensity-matched model and thus, were excluded from the analysis. Alternatively, we could have decreased the number of controls we utilized in our propensity matching; however, this may have resulted in a biased matching system. Furthermore, there was no difference in baseline characteristics and outcomes in the total smokers compared to the smokers we utilized after propensity matching. In addition, missing pertinent data variables include the timing of pneumonia and whether it was community acquired or nosocomial, the bacterial pathogen, and means of diagnosis of pneumonia (i.e., clinical vs. culture). Urine markers indicating recent cigarette smoke exposure, as well as pulmonary functional status (i.e., baseline incentive spirometer or pulmonary function testing) are not available within the TQIP database. Also, given that smoking is a selfreported variable, it is highly likely the incidence is significantly underreported, especially in an adolescent population that may be apprehensive to disclose illegal conduct. In addition, limitations of the database include the lack of granularity regarding the smoking history including the number of cigarettes smoked daily as well as how many years of smoking previously occurred. Although the non-smoking group had not smoked within the past 12 months, the percentage of ex-smokers in this group is not available within the database. Finally, there are no data within TQIP regarding other forms of smoking such as vaping. Despite these limitations, we are the first to evaluate adolescent smokers using a large trauma database and our study is strengthened by its generalizability.

\section{Conclusion}

In this 3-year review of the TQIP database, 3.1\% of adolescent trauma patients were found to be smokers. In support of our hypothesis, there was nearly triple the rate of pneumonia among the smokers, compared to propensity-matched nonsmokers. However, there was no difference in the rate of ARDS with only three cases of an adolescent trauma patient developing this complication. Future research is needed to target this at-risk adolescent trauma population for smoking cessation counseling to help decrease the risk of pneumonia and reduce hospital costs. In addition, trauma providers should be aware of the significantly increased rate of pneumonia in this population to either mitigate the risk or diagnose and treat this population early in the hopes of reducing associated morbidity like the increased LOS observed in this study.
Funding This research did not receive any specific grant from funding agencies in the public, commercial, or not-for-profit sectors.

\section{Compliance with ethical standards}

Conflict of interest The authors declare that they have no conflicts of interest.

Ethical approval This research involved humans. However, since this retrospective study was performed using a national database with deidentified patients, risk to participants is minimal.

Informed consent There is no consent required.

\section{References}

1. National Center for Chronic Disease Prevention and Health Promotion (US) Office on Smoking and Health (2014) The health consequences of smoking- 50 years of progress: a report of the surgeon general. Centers for Disease Control and Prevention (US), Atlanta, GA

2. Collaborators GBDRF (2016) Global, regional, and national comparative risk assessment of 79 behavioural, environmental and occupational, and metabolic risks or clusters of risks, 1990-2015: a systematic analysis for the Global Burden of Disease Study 2015. Lancet 388(10053):1659-1724. https://doi.org/10.1016/ S0140-6736(16)31679-8

3. Centers for Disease Control and Prevention (2019) Youth and tobacco use. https://www.cdc.gov/tobacco/data_statistics/fact sheets/youth_data/tobacco_use/index.htm. Accessed 01 May 2019

4. Busen NH, Modeland V, Kouzekanani K (2001) Adolescent cigarette smoking and health risk behavior. J Pediatr Nurs 16(3):187193. https://doi.org/10.1053/jpdn.2001.24182

5. Dearden KA, Crookston BT, De La Cruz NG, Lindsay GB, Bowden A, Carlston L, Gardner P (2007) Teens in trouble: cigarette use and risky behaviors among private, high school students in La Paz Bolivia. Rev Panam Salud Publica 22(3):160-168

6. Ellickson PL, Tucker JS, Klein DJ (2001) High-risk behaviors associated with early smoking: results from a 5-year follow-up. J Adolesc Health 28(6):465-473

7. Li H, Ma N, Wang J, Wang Y, Yuan C, Wu J, Luo M, Yang J, Chen J, Shi J, Liu X (2018) Nicotine induces progressive properties of lung adenocarcinoma A549 cells by inhibiting cystic fibrosis transmembrane conductance regulator (CFTR) expression and plasma membrane localization. Technol Cancer Res Treat 17:1533033818809984. https://doi.org/10.1177/1533033818 809984

8. Lu Q, Sakhatskyy P, Grinnell K, Newton J, Ortiz M, Wang Y, Sanchez-Esteban J, Harrington EO, Rounds S (2011) Cigarette smoke causes lung vascular barrier dysfunction via oxidative stress-mediated inhibition of RhoA and focal adhesion kinase. Am J Physiol Lung Cell Mol Physiol 301(6):L847-857. https:// doi.org/10.1152/ajplung.00178.2011

9. Rounds S, Lu Q (2018) Cigarette smoke alters lung vascular permeability and endothelial barrier function (2017 Grover Conference Series). Pulm Circ 8(3):2045894018794000. https://doi. org/10.1177/2045894018794000

10. Vargas Buonfiglio LG, Borcherding JA, Frommelt M, Parker GJ, Duchman B, Vanegas Calderon OG, Fernandez-Ruiz R, Noriega JE, Stone EA, Gerke AK, Zabner J, Comellas AP (2018) Airway surface liquid from smokers promotes bacterial growth and 
biofilm formation via iron-lactoferrin imbalance. Respir Res 19(1):42. https://doi.org/10.1186/s12931-018-0743-x

11. Arcavi L, Benowitz NL (2004) Cigarette smoking and infection. Arch Intern Med 164(20):2206-2216. https://doi.org/10.1001/ archinte.164.20.2206

12. Reilly JP, Christie JD (2015) Primed for injury: cigarette smokers and acute respiratory distress syndrome. Crit Care Med 43(9):2015-2016. https://doi.org/10.1097/CCM.0000000000 001121

13. Maouche K, Medjber K, Zahm JM, Delavoie F, Terryn C, Coraux C, Pons S, Cloez-Tayarani I, Maskos U, Birembaut P, Tournier JM (2013) Contribution of alpha7 nicotinic receptor to airway epithelium dysfunction under nicotine exposure. Proc Natl Acad Sci USA 110(10):4099-4104. https://doi.org/10.1073/pnas.12169 39110

14. Stabile AM, Marinucci L, Balloni S, Giuliani A, Pistilli A, Bodo M, Rende M (2018) Long term effects of cigarette smoke extract or nicotine on nerve growth factor and its receptors in a bronchial epithelial cell line. Toxicol Vitro 53:29-36. https://doi. org/10.1016/j.tiv.2018.07.020

15. Ahmad S, Zafar I, Mariappan N, Husain M, Wei CC, Vetal N, Eltoum IA, Ahmad A (2018) Acute pulmonary effects of aerosolized nicotine. Am J Physiol Lung Cell Mol Physiol. https://doi. org/10.1152/ajplung.00564.2017

16. Schweitzer KS, Hatoum H, Brown MB, Gupta M, Justice MJ, Beteck B, Van Demark M, Gu Y, Presson RG Jr, Hubbard WC, Petrache I (2011) Mechanisms of lung endothelial barrier disruption induced by cigarette smoke: role of oxidative stress and ceramides. Am J Physiol Lung Cell Mol Physiol 301(6):L836-846. https://doi.org/10.1152/ajplung.00385.2010

17. Morrison D, Rahman I, Lannan S, MacNee W (1999) Epithelial permeability, inflammation, and oxidant stress in the air spaces of smokers. Am J Respir Crit Care Med 159(2):473-479. https:// doi.org/10.1164/ajrccm.159.2.9804080

18. Prin M, Li G (2016) Complications and in-hospital mortality in trauma patients treated in intensive care units in the United States, 2013. Inj Epidemiol 3(1):18. https://doi.org/10.1186/s4062 1-016-0084-5

19. Watkins TR, Nathens AB, Cooke CR, Psaty BM, Maier RV, Cuschieri J, Rubenfeld GD (2012) Acute respiratory distress syndrome after trauma: development and validation of a predictive model. Crit Care Med 40(8):2295-2303. https://doi.org/10.1097/ CCM.0b013e3182544f6a

20. Iribarren C, Jacobs DR Jr, Sidney S, Gross MD, Eisner MD (2000) Cigarette smoking, alcohol consumption, and risk of ARDS: a 15-year cohort study in a managed care setting. Chest 117(1):163-168

21. Moazed F, Hendrickson C, Nelson M, Conroy A, Cohen MJ, Calfee CS (2018) Platelet aggregation after blunt trauma is associated with the acute respiratory distress syndrome and altered by cigarette smoke exposure. J Trauma Acute Care Surg 84(2):365-371. https://doi.org/10.1097/TA.0000000000001738

22. Bagaitkar J, Demuth DR, Scott DA (2008) Tobacco use increases susceptibility to bacterial infection. Tob Induc Dis 4:12. https:// doi.org/10.1186/1617-9625-4-12

23. Mason GR, Uszler JM, Effros RM, Reid E (1983) Rapidly reversible alterations of pulmonary epithelial permeability induced by smoking. Chest 83(1):6-11

24. McRitchie DI, Matthews JG, Fink MP (1995) Pneumonia in patients with multiple trauma. Clin Chest Med 16(1):135-146

25. Baker AM, Meredith JW, Haponik EF (1996) Pneumonia in intubated trauma patients Microbiology and outcomes. Am J Respir Crit Care Med 153(1):343-349. https://doi.org/10.1164/ajrcc m.153.1.8542141

26. Leonard KL, Borst GM, Davies SW, Coogan M, Waibel BH, Poulin NR, Bard MR, Goettler CE, Rinehart SM, Toschlog EA
(2016) Ventilator-associated pneumonia in trauma patients: different criteria. Differ Rates Surg Infect 17(3):363-368. https://doi. org/10.1089/sur.2014.076

27. Park HO, Kang DH, Moon SH, Yang JH, Kim SH, Byun JH (2017) Risk factors for pneumonia in ventilated trauma patients with multiple rib fractures. Korean J Thorac Cardiovasc Surg 50(5):346-354. https://doi.org/10.5090/kjtcs.2017.50.5.346

28. Austin PC (2011) Optimal caliper widths for propensity-score matching when estimating differences in means and differences in proportions in observational studies. Pharma Stat 10(2):150-161. https://doi.org/10.1002/pst.433

29. Panzer AR, Lynch SV, Langelier C, Christie JD, McCauley K, Nelson M, Cheung CK, Benowitz NL, Cohen MJ, Calfee CS (2018) Lung microbiota is related to smoking status and to development of acute respiratory distress syndrome in critically Ill trauma patients. Am J Respir Crit Care Med 197(5):621-631. https://doi.org/10.1164/rccm.201702-0441OC

30. Calfee CS, Matthay MA, Kangelaris KN, Siew ED, Janz DR, Bernard GR, May AK, Jacob P, Havel C, Benowitz NL, Ware LB (2015) Cigarette smoke exposure and the acute respiratory distress syndrome. Crit Care Med 43(9):1790-1797. https://doi. org/10.1097/CCM.0000000000001089

31. Hsieh SJ, Zhuo H, Benowitz NL, Thompson BT, Liu KD, Matthay MA, Calfee CS, National Heart L, Blood Institute Acute Respiratory Distress Syndrome N, National Heart L, Blood Institute Acute Respiratory Distress Syndrome N (2014) Prevalence and impact of active and passive cigarette smoking in acute respiratory distress syndrome. Crit Care Med 42(9):2058-2068. https://doi. org/10.1097/CCM.0000000000000418

32. Calfee CS, Matthay MA, Eisner MD, Benowitz N, Call M, Pittet JF, Cohen MJ (2011) Active and passive cigarette smoking and acute lung injury after severe blunt trauma. Am J Respir Crit Care Med 183(12):1660-1665. https://doi.org/10.1164/rccm.20101 $1-1802 \mathrm{OC}$

33. Johnston CJ, Rubenfeld GD, Hudson LD (2003) Effect of age on the development of ARDS in trauma patients. Chest 124(2):653-659

34. de Roulet A, Burke RV, Lim J, Papillon S, Bliss DW, Ford HR, Upperman JS, Inaba K, Jensen AR (2018) Pediatric traumaassociated acute respiratory distress syndrome: Incidence, risk factors, and outcomes. J Pediatr Surg. https://doi.org/10.1016/j. jpedsurg.2018.07.005

35. Killien EY, Mills B, Watson RS, Vavilala MS, Rivara FP (2018) Risk Factors on hospital arrival for acute respiratory distress syndrome following pediatric trauma. Crit Care Med 46(12):e1088e1096. https://doi.org/10.1097/CCM.0000000000003379

36. Lee KY (2017) Pneumonia, acute respiratory distress syndrome, and early immune-modulator therapy. Int J Mol Sci. https://doi. org/10.3390/ijms18020388

37. Liu Y, Pleasants RA, Croft JB, Wheaton AG, Heidari K, Malarcher AM, Ohar JA, Kraft M, Mannino DM, Strange C (2015) Smoking duration, respiratory symptoms, and COPD in adults aged $\% 3 \mathrm{e} /=45$ years with a smoking history. Int J Chronic Obstr Pulm Dis 10:1409-1416. https://doi.org/10.2147/COPD.S82259

38. Ferro TN, Goslar PW, Romanovsky AA, Petersen SR (2010) Smoking in trauma patients: the effects on the incidence of sepsis, respiratory failure, organ failure, and mortality. J Trauma 69(2):308-312. https://doi.org/10.1097/TA.0b013e3181e1761e

39. Niederman MS, McCombs JS, Unger AN, Kumar A, Popovian R (1998) The cost of treating community-acquired pneumonia. Clin Ther 20(4):820-837

40. Zhang S, Sammon PM, King I, Andrade AL, Toscano CM, Araujo SN, Sinha A, Madhi SA, Khandaker G, Yin JK, Booy R, Huda TM, Rahman QS, El Arifeen S, Gentile A, Giglio N, Bhuiyan MU, Sturm-Ramirez K, Gessner BD, Nadjib M, Carosone-Link PJ, Simoes EA, Child JA, Ahmed I, Bhutta ZA, Soofi SB, Khan 
RJ, Campbell H, Nair H (2016) Cost of management of severe pneumonia in young children: systematic analysis. J Glob Health 6(1):010408. https://doi.org/10.7189/jogh.06.010408

41. Nahmias J, Doben A, Poola S, Korntner S, Carrens K, Gross R (2016) Implementation of a quality improvement project on smoking cessation reduces smoking in a high risk trauma patient population. World J Emerg Surg WJES 11:15. https://doi.org/10.1186/ s13017-016-0072-7

42. Bell TM, Bayt DR, Zarzaur BL (2015) "Smoker's paradox" in patients treated for severe injuries: lower risk of mortality after trauma observed in current smokers. Nicotine Tob Res 17(12):1499-1504. https://doi.org/10.1093/ntr/ntv027

43. Knowlin L, Stanford L, Cairns B, Charles A (2017) The effect of smoking status on burn inhalation injury mortality. Burns 43(3):495-501. https://doi.org/10.1016/j.burns.2016.09.003

44. Aune E, Roislien J, Mathisen M, Thelle DS, Otterstad JE (2011) The "smoker's paradox" in patients with acute coronary syndrome: a systematic review. BMC Med 9:97. https://doi. org/10.1186/1741-7015-9-97

45. Chen KY, Rha SW, Li YJ, Jin Z, Minami Y, Park JY, Poddar KL, Ramasamy S, Wang L, Li GP, Choi CU, Oh DJ, Jeong MH, Korea Acute Myocardial Infarction Registry I (2012) 'Smoker's paradox' in young patients with acute myocardial infarction. Clin Exp Pharmacol Physiol 39(7):630-635. https://doi.org/10.111 1/j.1440-1681.2012.05721.x

46. Andrikopoulos GK, Richter DJ, Dilaveris PE, Pipilis A, Zaharoulis A, Gialafos JE, Toutouzas PK, Chimonas ET (2001) In-hospital mortality of habitual cigarette smokers after acute myocardial infarction; the "smoker's paradox" in a countrywide study. Eur Heart J 22(9):776-784. https://doi.org/10.1053/euhj.2000.2315

47. Glynn MF, Mustard JF, Buchanan MR, Murphy EA (1966) Cigarette smoking and platelet aggregation. Can Med Assoc J 95(11):549-553

48. Giaccia AJ, Simon MC, Johnson R (2004) The biology of hypoxia: the role of oxygen sensing in development, normal function, and disease. Genes Dev 18(18):2183-2194. https://doi.org/10.1101/ gad. 1243304

Publisher's Note Springer Nature remains neutral with regard to jurisdictional claims in published maps and institutional affiliations. 